\title{
СПЕЦИФИКА ФИНАНСОВОГО МЕХАНИЗМА ПОДДЕРЖКИ БИЗНЕС- ПРОЦЕССОВ ИНДУСТРИИ КУЛЬТУРЫ И ТВОРЧЕСТВА
}

\author{
(c) 2018 Мальшина Наталья Анатольевна \\ кандидат философских наук, доцент \\ Саратовская государственная консерватория имени Л.В. Собинов \\ 410012, г. Саратов, просп. им. Кирова С.М., д. 1 \\ докторант \\ Институт исследования товародвижения и конъюнктуры оптового рынка \\ 125319, Москва, ул. Черняховского, 16 \\ E-mail:malsnataliya@yandex.ru
}

В статье рассматривается рынок креативной индустрии, который абсолютно не похож на другие рынки по нескольким объяснениям - сама услуга не существует до момента ее предоставления. Поэтому оценить данные услуги, а тем более дать ей какую-либо оценку до их получения - невозможно; услугам креативной индустрии свойственна высокая степень неопределенности, что ставит клиента в невыгодное положение, а продавцам затрудняет продвижение услуг на рынок. В теоретическом анализе соотношение креативных, творческих индустрии и инноваций очень разнообразно и изучение его позволяет выявить эмпирические и аналитические связей между творческими индустриями и инновациями (инновационной политикой). Рост творческих индустрий можно рассматривать как результат успешных инновационных процессов в традиционных секторах экономики, которые позволяют производить тот же объем продукции, используя меньший объем ресурсов. Для некоторых отраслей экономики материальные и финансовые преимущества от сотрудничества со сферой культуры и искусства очевидны, поэтому активные услуги культуры характеризуются определенной степенью инновационности и чертами креативности. Составляющие поддержки процесса предоставления услуг культуры могут развиваться и усложняться, если увеличивается спрос и покупательская способность населения конкретного субъекта РФ или роста возможностей инвестиций. Поддержка может сокращаться, если нарушается баланс между спросом, процессом предоставления и инвестиционной активностью. Также существует возможность прорыва, скачка в процессе поддержки индустрии культуры - появление новых информационных и других технологий. Составляющие процесса предоставления услуг культуры с использованием логистического подхода включает: внутреннюю логистику: сбор данных, обслуживание, работа с клиентами и персоналом и др.; маркетинг: продвижение и продажа билетов и услуг, сопутствующих товаров, реклама, информационное обеспечение, подготовка предложений и др.; внешняя логистика: обработка заказов, доставка инструментов и персонала, подготовка отчетности; предоставление услуг: непосредственный контакт потребителя и производителя услуг в результате реализации услуги культуры; постреализационное обслуживание: поддержка клиентов, обратная связь с потребителями, регулирование рекламаций, ремонт и др. Выводы. Соединяя с одной стороны этапы процесса предоставления услуг креативной индустрии и меры поддержки возможно составить матрицу поддержки процесса предоставления услуг культуры, демонстрирующую связь между мерами поддержкой услуг культуры и процессом предоставления услуг индустрии культуры.

Ключевые слова: матрица и институты процесса поддержки предоставления услуг индустрии культуры, творческий потенциал, креативный класс, эндаумент-фонды.

Введение. Общепринято, выделение основных специфических характеристик услуг: не материальность, не постоянство качества, не способность к хранению, одновременность потребления и предоставления, отсутствие владельца-собственника услуг. Исходя из этих особенностей определяются и особенности рынка услуг: менее монополизирован (рассредоточен), экономия за счет разнообразия и качества услуг; конъюнктурность (непредсказуемость); сегментация (ориентированность на определенную группу покупателей, комплементарность и взаимозаменяемость услуг); локализация (привязанность к конкретной территории); дина- 
мизмом и гибкость (скорость оборота капитала высокая, меньше первоначальный капитал, основа - малый бизнес).

Рынок услуг создает условия для развития предпринимательства, в силу большой скорости оборота капитала и задействуй множества малых предприятий, способствующих занятости большого количества экономически активного населения, что ведет к формированию среднего класса, предотвращению экономического, социального, политического и иного давления.

Исходя из вышеуказанных отличительных характеристик услуги, можно выделить некоторые особенности спроса на услуги культуры: сезонность; индивидуальность; местный характер; определенные сложности с гибкостью предложения. Исходя из вышеуказанных отличительных характеристик услуги, можно выделить некоторые особенности спроса на услуги: сезонность; индивидуальность; местный характер; определенные сложности с гибкостью предложения.

Спрос на услуги всегда индивидуален, предшествует их производству, имеет местный характер, практически не взаимозаменяем.

Потребление услуг культуры, в отличие от потребления материальных благ не имеет ограничений. Потребитель обычно формирует спрос на услуги нескольких видов. Развитая сфера бытовых услуг позволяет высвободить время для развлечений, развитие туризма увеличивает спрос на услуги связи, общественного питания и др.

Высокая общественная значимость социально-культурных услуг (здравоохранение, образование, культура) определяет наличие льгот, дотаций, бесплатность предоставления отдельных услуг.

Неравномерность спроса на услуги культуры по временам года, периодам суток, дням недели и невозможность накапливать, хранить услуги порождает необходимость регулирования тарифами интенсивности спроса во времени через гибкое ценообразование, дифференцированное ценообразование, использование механизмов скидок и надбавок. Предельные возможности некоторых систем обслуживания не отличаются гибкостью. Объем деятельности производственных систем можно увеличить на короткий срок, например, с помощью сверхурочных работ и дополнительных смен. Некоторые фирмы по оказанию услуг тоже могут увеличить объемы своей деятельности, продлив часы работы, как, например, делают парки с аттракционами в летние месяцы.

Колебания спроса присущи практически всем видам услуг. Методологические предпосылки его изучения заключаются в том, что спрос есть величина, изменяющаяся во времени под влиянием следующих факторов: социально-демографических; экономических; сезонных; психологических.

Рассмотрим подробнее влияние указанных выше факторов на платежеспособный спрос в сфере услуг. Среди социальных факторов роста спроса на услуги в первую очередь необходимо отметить увеличение продолжительности свободного времени населения (сокращение рабочего времени, увеличение продолжительности ежегодных отпусков), что в сочетании с повышением уровня жизни населения означает приток новых потенциальных клиентов в сферу услуг. Также постоянное влияние на спрос в сфере услуг оказывают демографические факторы, касающиеся численности населения, размещения его по отдельным странам и регионам, половозрастной структуры (с выделением трудоспособного населения, учащихся, пенсионеров), семейного положения и состава семей. Влияние экономических факторов главным образом обусловлено тем, что между тенденциями развития сферы услуг и экономики наблюдается тесная взаимозависимость.

В сфере услуг культуры в большей степени, чем в материальном производстве, необходимо учитывать фактор времени (сезонные спады в спросе, пиковые периоды спроса в течение суток). Наиболее наглядно это видно на примере транспортных услуг. Спрос зависит от времени года, дней недели, так как в летнее время и в выходные дни количество пассажиров увеличивается. Здесь велика роль планирования мощностей (пропускной способности сферы услуг).

Большинство покупателей услуг культуры не придерживаются строгой рациональности в процессе приобретения, что подразумевало бы выявление всех возможных источников приобретения услуг и применение к каждому из них критериев оценки. Однако очевидно, что организационные покупатели действуют с большей рациональностью, чем индивидуальные потребители, которые демонстрируют большую нелогичность в принятии решения о покупке. Корпоративный потребитель скорее предпочтет 
простой и относительно менее рискованный подход, приобретая знакомую услугу, чем будет тратить время на поиск и анализ всех возможных вариантов.

Таким образом, специфика динамики платежеспособного спроса на услугу культуры обусловлена такими ее особенностями, как неосязаемость, несохраняемость, неотделимость от источника, непостоянство качества. Колебания спроса присущи практически всем видам услуг культуры и зависят от социально-демографических, экономических, сезонных и психологических факторов. То есть изменению спроса свойственны закономерности, качественный анализ которых позволяет дифференцировать объем и структуру потребления населением отдельных видов услуг.

Рынок услуг культуры абсолютно не похож на другие рынки. Этому есть несколько объяснений. Во-первых, сама услуга не существует до момента ее предоставления. Поэтому оценить услугу культуры, а тем более дать ей какую-либо оценку до ее получения - невозможно. Во-вторых, услугам культуры свойственна высокая степень неопределенности, что ставит клиента в невыгодное положение, а продавцам затрудняет продвижение услуг на рынок. Спрос на услуги более индивидуален, в отличие от спроса на товары, поэтому рынок услуг отличается большей ориентацией на определенную группу покупателей. Спрос на услуги культуры довольно сложно прогнозировать, что связано как со специфическими особенностями услуг, в частности с неспособностью к хранению, так и с тем, что часто решение о потребление услуг принимается спонтанно. Спрос также завит от сезонного фактора, от общего уровня благосостояния населения.

Теоретический анализ. Сфера услуг культуры находящаяся на пересечении различных направлений деятельности и должна изучаться с учётом системы факторов: экономических, социальных, культурных, политических, технологических, психологических и др. Предпринимательство в сфере культурных и творческих индустрий осложняется такими обстоятельствами, как широкая дифференциация продуктов и услуг, необходимость производить товары, которые имеют художественную ценность (природу), субъективную оценку со стороны потребителя, необходимость работать с людьми, которые часто более контент-ориентированы, чем на- целены на получение прибыли. В сущности, культурного и творческого предпринимателя можно охарактеризовать как человека, который использует предпринимательские принципы для осуществления своей творческой деятельности на коммерческой основе. Однако, достижение баланса между «культурной основой творчества» и предпринимательской деятельностью не является однозначным и зависит от типа творческой индустрии.

Соотношение творческих индустрии и инноваций очень разнообразно и изучение его позволяет выявить эмпирические и аналитические связей между творческими индустриями и инновациями (инновационной политикой). Творческие индустрии, производят результат деятельности в виде товара или услуги (в том числе идеи), которые впоследствии становится ресурсами для процесса инноваций и в других отраслях экономики как в научном, так и в технологическом смысле [3].

Исследуя соотношение рынка услуг и производственного рынка - рост творческих индустрий можно рассматривать как результат успешных инновационных процессов в традиционных секторах экономики, которые позволяют производить тот же объем продукции, используя меньший объем ресурсов. За счет роста производительности в основных секторах экономики высвобождаются ресурсы, как человеческие, так и не материальные, которые могут быть использованы в секторе услуг культуры как фактор роста и следовательно как основа для устойчивого роста творческих индустрий.

Основой возрастающей роли творческих индустрий в инновационном процессе возможно рассматривать концепцию «креативного класса» [4], объясняющейся появление нового класса людей в быстро меняющейся экономике постиндустриального общества, как новое социальное общекультурное явление. Р. Флорида пишет, что «креативность выступает в качестве наиболее ценного ресурса новой экономики, сама собственно товаром не являясь, что подъем креативной экономики соединяет сферы технических новаций, бизнеса и культуры» [4, с. 12].

Высокая степень реализации творческого потенциала представителей сферы культуры и искусства положительно влияет на производительность знания другими работниками, что способствует увеличению производительности и росту доходов. Коммуникации людей с пред- 
ставителями сферы искусства стимулируют новые идеи - «технологическая и экономическая креативность, рождается и создается при взаимодействии с художественной и культурной креативностью». [4, с.5].

Для некоторых отраслей экономики материальные и финансовые преимущества от сотрудничества со сферой культуры и искусства очевидны, и в основном это сферы, активно использующие культурные блага и символический капитал культуры и искусства как ресурсы (реклама, дизайн, IT-продукты развлекательного характера и т.д.). В настоящий момент механизмы, посредством которых знания и креативность перетекают из одного сектора в другой, остаются малоисследованными и порождают необходимость дальнейших исследований [3]. Поэтому активные услуги культуры характеризуются определенной степенью инновационности и чертами креативности.

Результаты. Одной из самых важных стратегических целей развития сферы культуры представляется - инновационная модель финансирования услуг культуры [5]. Она представляет собой комбинацию: института бюджетных нормативов; института маркированных налогов; института индивидуальных бюджетных назначений; института эндаумент-фондов [5]. Представляется необходимым более подробно остановится на такой форме налогового протекционизма как маркированные налоги - специальные налоги, предусматривающие прямое направление в сферу культуры доходов от товаров и услуг, наносящих вред человеку. Часть подоходного налога, в пределах $2 \%$, направляется на социально-культурные нужды, предоставляя возможность свободного выбора приоритетных направлений расходов.

Система фондов целевого капитала индустрии культуры в комбинации с уже рассмотренными механизмами предусматривает формирование отраслевых эндаумент-фондов в форме независимых некоммерческих организаций на региональном и федеральном уровнях для различных видов культурной деятельности.

Суммируя все рассмотренные, меры государственной, государственно-частной и не государственной поддержки многоуровневой системы услуг индустрии культуры представляется необходимым формирование матрица мер поддержки и бизнес-процессов индустрии культуры в виде рисунка и схемы (рисунок 1, табл. 1). Достижение стратегически важных и операционных целей стоящих перед индустрией культуры достигается при реализации платных и бесплатных услуг культуры в интегрированных системах конкретных субъектов РФ. Тем самым снимается первоначальное сопротивление инновационным структурам, возникает межотраслевая и межбюджетная интеграция, снимается только линейная направленность деятельности (т.к. возникают обратные связи от рынков услуг, влияющих на параметры и показатели услуг культуры), снимается технократизм [1, с. 49], характерный для кластерного подхода.

Составляющие поддержки процесса предоставления услуг культуры могут развиваться и усложняться, если увеличивается спрос и покупательская способность населения конкретного субъекта РФ или роста возможностей инвестиций. Поддержка может сокращаться, если нарушается баланс между спросом, процессом предоставления и инвестиционной активностью. Также существует возможность прорыва,

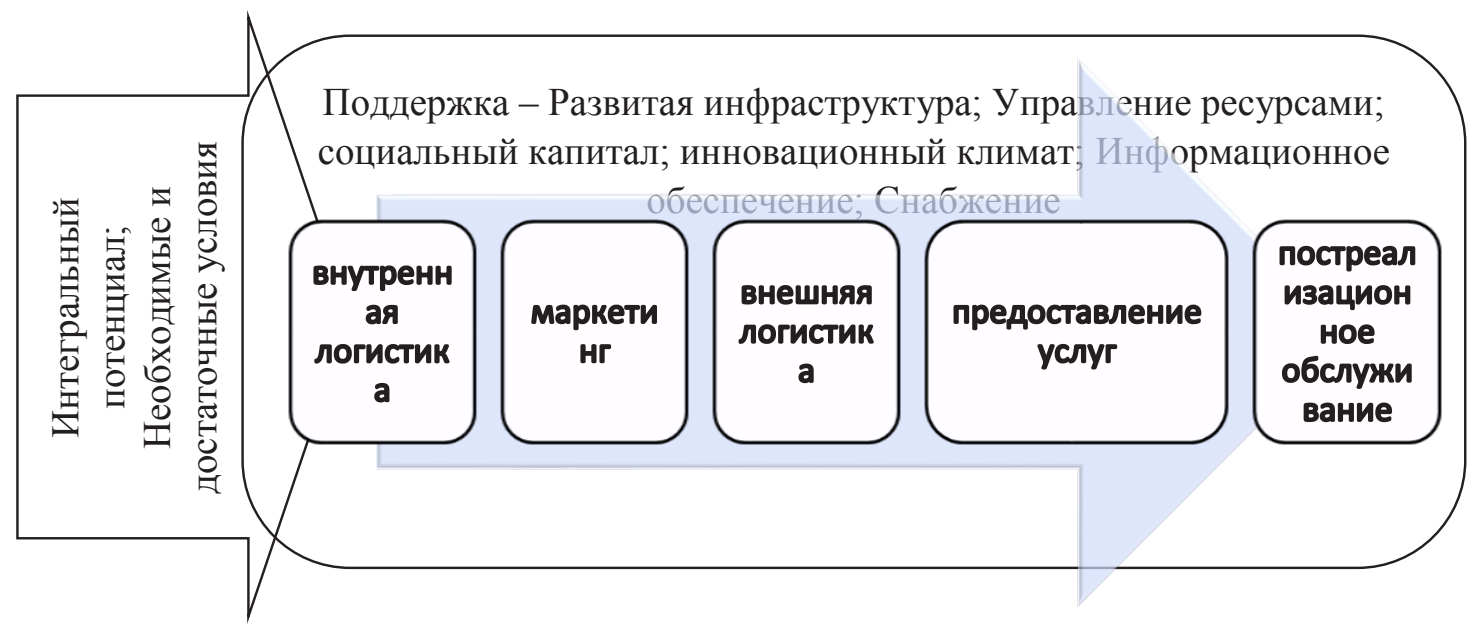

Puc. 1. Составляющие процесса поддержки предоставления услуг индустрии культуры 
скачка в процессе поддержки индустрии культуры - появление новых информационных и других технологий.

Составляющие процесса предоставления услуг культуры с использованием логистического подхода включает:

1. Внутреннюю логистику: сбор данных, обслуживание, работа с клиентами и персоналом и др.;

2. Маркетинг: продвижение и продажа билетов и услуг, сопутствующих товаров, реклама, информационное обеспечение, подготовка предложений и др.;

3. Внешняя логистика: обработка заказов, доставка инструментов и персонала, подготовка отчетности;

4. Предоставление услуг: непосредственный контакт потребителя и производителя услуг в результате реализации услуги культуры;

5. Постреализационное обслуживание: поддержка клиентов, обратная связь с потребителями, регулирование рекламаций, ремонт и др.

В процессе производства услуг культуры могут участвовать и коммерческие и не коммерческие организации, и даже социальные группы.

Исходя из потенциала конкретного субъекта поддержки выбираются и виды поддержки: развитие инфраструктуры; управление ресурсопотоковыми процессами; социальный капитал; инновационный климат; информационное обеспечение; снабжение (инструментами, рекламой и площадью и др.). данные виды поддержки могут осуществляться как государственными, так и не государственными организациями и предприятиями различных областей экономики.

Соединяя с одной стороны этапы процесса предоставления услуг культуры и меры поддержки возможно матрицу поддержки процесса предоставления услуг культуры, демонстрирующую связь между мерами поддержкой услуг культуры и процессом предоставления услуг индустрии культуры. В зависимости от специфики отраслевой системы конкретного субъекта структура матрицы может меняться.

В данном смысле услуги индустрии культуры являются инновационным продуктом и прослеживается качественная зависимость между предоставлением услуг, прибылью и жизненным циклом услуг культуры и мерами поддержки услуг индустрии культуры.

В зависимости от этапа процесса поддержки предоставления услуг индустрии культуры институтами поддержки могут являться: государство; некоммерческие организации - грандодатели; коммерческие предприятия; фонды «посевных» инвестиций; «Бизнес-ангелы»; венчурные фонды; банки; фонды прямых инвестиций.

Помощь в работе на соответствующих стадиях процесса может являться задачей инфраструктурных организаций сферы культуры, объединенных единым процессом обеспечения и предоставления услуг культуры. Данные инфраструктурные организации поддержки услуг культуры могут иметь специфические условия

Таблица 1. Матрица организации и мер поддержки услуг культуры

\begin{tabular}{|c|c|c|c|c|c|}
\hline \multirow[b]{2}{*}{$\begin{array}{l}\text { Институты } \\
\text { поддержки }\end{array}$} & \multicolumn{5}{|c|}{ Меры поддержки } \\
\hline & $\begin{array}{l}\text { Внутренняя } \\
\text { логистика }\end{array}$ & Маркетинг & $\begin{array}{c}\text { Внешняя } \\
\text { логистика }\end{array}$ & $\begin{array}{c}\text { Предоставле- } \\
\text { ние услуг }\end{array}$ & $\begin{array}{c}\text { Постреализа- } \\
\text { ционное обслу- } \\
\text { живание }\end{array}$ \\
\hline $\begin{array}{c}\text { Государствен- } \\
\text { ные организа- } \\
\text { ции }\end{array}$ & $\begin{array}{c}\text { Программы } \\
\text { развития отрас- } \\
\text { левых мини- } \\
\text { стерств }\end{array}$ & СМИ & $\begin{array}{c}\text { Программы } \\
\text { развития отрас- } \\
\text { левых мини- } \\
\text { стерств }\end{array}$ & $\begin{array}{c}\text { Государствен- } \\
\text { но-частное } \\
\text { партнерство, } \\
\text { государственные } \\
\text { программы }\end{array}$ & $\begin{array}{c}\text { Государствен- } \\
\text { ные институты } \\
\text { развития }\end{array}$ \\
\hline $\begin{array}{c}\text { Коммерческие } \\
\text { организации }\end{array}$ & $\begin{array}{l}\text { Частные гран- } \\
\text { ты, венчурные } \\
\text { фонды, фонды } \\
\text { «посевных» } \\
\text { инвестиций }\end{array}$ & $\begin{array}{c}\text { Частные фирмы, } \\
\text { банки }\end{array}$ & $\begin{array}{c}\text { Частные гран- } \\
\text { ты, венчурные } \\
\text { фонды, }\end{array}$ & $\begin{array}{c}\text { Корпоративные } \\
\text { и торгово-раз- } \\
\text { влекательные } \\
\text { центры, форды } \\
\text { прямых инве- } \\
\text { стиций } \\
\end{array}$ & $\begin{array}{c}\text { Частные гран- } \\
\text { ты, венчурные } \\
\text { фонды }\end{array}$ \\
\hline $\begin{array}{c}\text { Некоммерческие } \\
\text { организации } \\
\text { (грандодатели), } \\
\text { общественный } \\
\text { сектор }\end{array}$ & $\begin{array}{c}\text { Грандодатели, } \\
\text { спонсоры, про- } \\
\text { фсоюзы }\end{array}$ & $\begin{array}{c}\text { Общественные } \\
\text { организации, } \\
\text { профессиональ- } \\
\text { ные союзы }\end{array}$ & $\begin{array}{c}\text { Грандодатели, } \\
\text { спонсоры }\end{array}$ & $\begin{array}{c}\text { Профессиональ- } \\
\text { ные ассоциации } \\
\text { и союзы }\end{array}$ & $\begin{array}{c}\text { Общественные } \\
\text { организации, } \\
\text { профессио- } \\
\text { нальные союзы, } \\
\text { грандодатели, } \\
\text { спонсоры }\end{array}$ \\
\hline
\end{tabular}


взаимодействия со всеми участниками цепочки процесса предоставления услуг индустрии культуры.

В настоящее время прослеживается необходимость в новых формах взаимодействия государственных структур, общественных организаций, некоммерческих организаций и бизнес-сообществом. Данные меры поддержки способны привести к созданию условий для привлечения инвестиций, повышения конкурентоспособности услуг культуры, эффективности функционирования индустрии культуры, модернизации инфраструктуры субъекта РФ, повышению качества услуг культуры.

Выводы. Развитие интегрированных логистических систем в индустрии культуры позволят эффективно решать задачи экономического роста депрессивных субъектов РФ [2]. Для реализации намеченных экономико-правовых проектов необходим профессиональный менеджмент сферы культуры. Таким образом, сочетание административных и экономических методов обеспечения эффективного управления - основное направление оптимизации экономико-правового механизма в сфере культуры.

\section{Библиографический список}

1. Колонтай М.М. Инновационный менеджмент. Минск. 1997. 191 с.

2. Мальшина Н.А. Модель совершенствования управления потоковыми процессами в интегрированных сервисных комплексах // Изв. Сарат. ун-та. Нов. сер. Сер. Экономика. Управление. Право. 2014. Т. 14, вып. 1. С. 163-167.

3. Матецкая М.В. Культурные индустрии как инновации в культуре, менеджменте, технологиях. URL: http:// www.hse.ru/data/2012/01/31/1269679204/Matetskaya_men_2011.pdf

4. Флорида Р. Креативный класс. Люди, которые меняют будущее. Москва.2013. 17 с.

5. Рубинштейн А.Я. Инновационная модель финансирования культуры // справочник руководителя учреждения культуры, 2016, № 2. С. 10-29.- https://www.cultmanager.ru/article/7535-qqess9-innovatsionnaya-modelfinansirovaniya-kultury

Поступила в редакцию 09.09.2018 